\title{
$\pm 32$
}

AMOCO PRODUCTION COMPANY

Tu1sa, Oklahoma

June 13, 1983

FILE: $\quad$ Technical Service 839146 SX

TO: W. S. Davis, Denver

ATTN: Kirk W. Sherwood

SUBJECT: Mineralogy of Chips from Exxon Pt. Thomson Wells No. 1 and 3

The attached table summarizes the semi-quantitative $x$-ray mineralogy of six samples from Exxon Pt. Thomson Wells No. 1 and 3 . As instructed, I am returning what remains of each sample (both unused and prepared) to Kirk Sherwood in Anchorage. If there are any questions about these results, please call me at the Research Center at Ext. 3477.

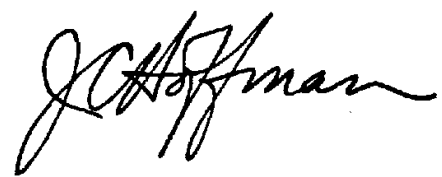

J. C. Hoffman

$\mathrm{JCH}: \mathrm{ceh}$

Attachment

cc: C. F. Upshaw/E. R. Michaelis

H. D. Winland

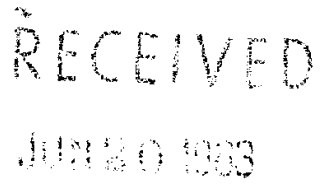


CAOTION: THESE ESTIMATES ART ONLY SEMI-QUANTITATIVE.

\section{X-RAY DIFFRACTION MINERAL PERCENTAGES}

LOCALITY: PT. THOMSON WELL NO. 1 AND 3.

FORMATION : unnamea

\section{AGR: CRETACEOUS}

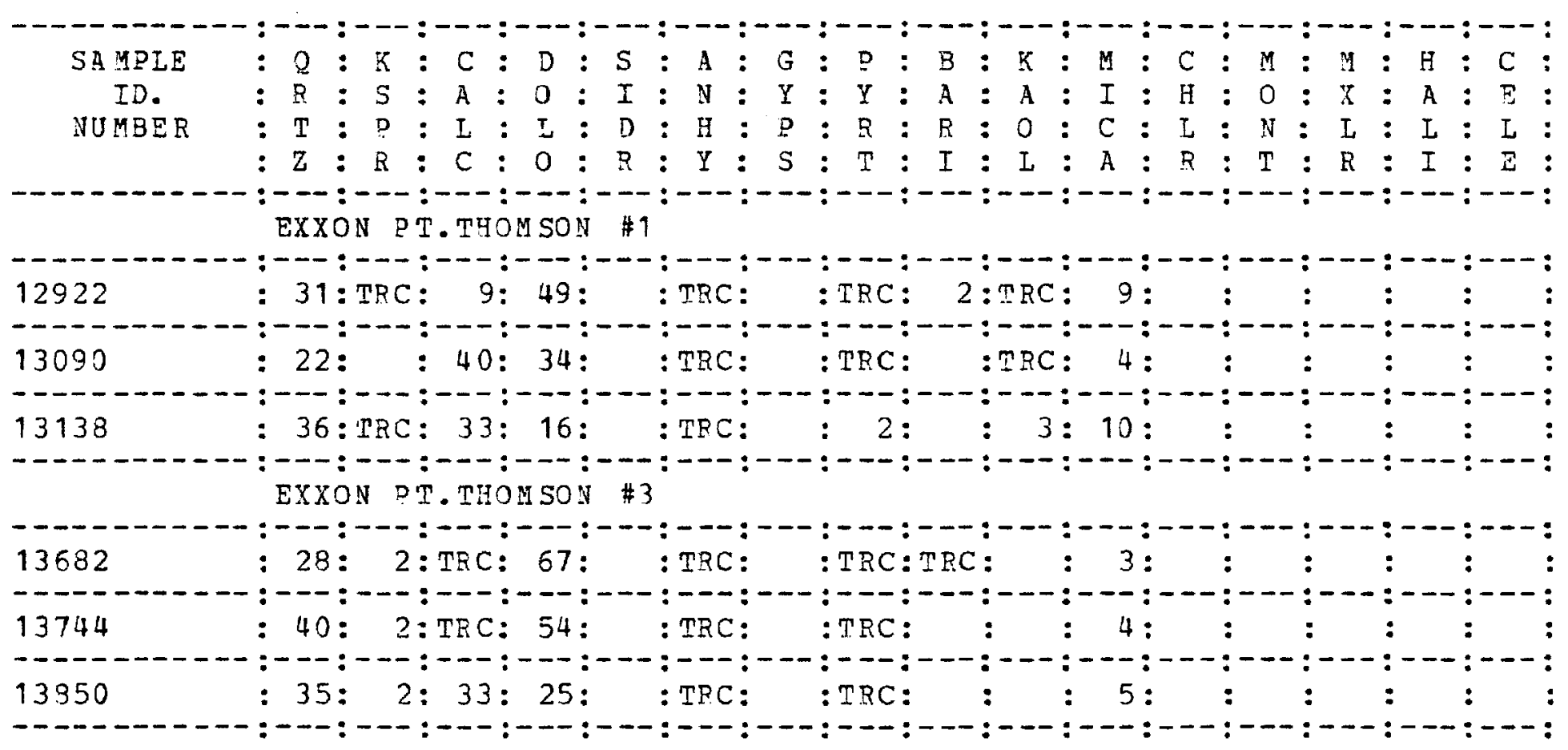

